\title{
Modelling wooden cultural heritage. The need to consider each artefact as unique as illustrated by the Cannone violin
}

\author{
Bertrand Marcon ${ }^{1}$, Giacomo Goli ${ }^{2 *}$ and Marco Fioravanti ${ }^{2}$
}

\begin{abstract}
This research work investigates the possibility to use a hygroscopic model based on Fick's law to predict the global moisture content variations an historical violin undergoes during a concert. To set up the model to work some input are required such as: the object geometries, the wood species used, the thicknesses, the moisture diffusion coefficients, the permeability of varnished surfaces, the anhydrous masses of the moisture exchanging parts, the sorption isotherms, information often far from being available or measurable. At a first extent, the model was run on the environmental conditions recorded during nine concerts played with the "Cannone" violin (1743) and the computed mass variations compared with the mass variations recorded during the same concerts. The model, set with simplifying conditions and with diffusion coefficients from literature, has shown a very little predictive capacity. On the other hand, the model was tuned on the experimental data using an inverse procedure for moisture diffusion coefficient identification. After the tuning the model has shown a very good predictive ability showing how Fick's low can be profitably used to assess the mass transfer in a complex heritage object such as a violin. This paper highlights the possibility to successfully use the Fick's law to model mass transfer in a violin but also makes evident how such models must be tuned with real measurements in order to be effective.
\end{abstract}

Keywords: Cultural heritage, Musical instrument, Environmental conditions, Moisture content, Guarneri violin, Fick's law, Modelling, Conservation

\section{Introduction}

Moisture content variations have important consequences on the dimensions, shape, stresses, physical and mechanical properties of wooden objects $[1,2]$. Anisotropic behaviour of wood, moisture gradients as well as asymmetric moisture adsorption in wooden cultural heritage is a large problem in the formation and grow of damage $[3,4]$. Approaches to measure and model the role of moisture gradients, constrained deformations, and resulting stresses have been undertaken since two decades in the field of panel paintings [5-13]. These research works were recently extended to musical instruments

\footnotetext{
*Correspondence: giacomo.goli@unifi.it

${ }^{2}$ Department of Agriculture, Food, Environment and Forestry (DAGRI),

University of Florence, Via S. Bonaventura 13, 50145 Florence, Italy

Full list of author information is available at the end of the article
}

[14], timber structures [15], and waterlogged wood [16]. The recent European COST Action FP1302 "- WOODen MUSical Instrument Conservation and Knowledge" was investigating the issue of playing cultural heritage musical instrument showing how important this topic is for the conservation of these objects [17]. The understanding of these phenomena is fundamental for conservation of cultural heritage such as the violin Guarneri "del Gesù" (1743) known as the "Cannone", the piece of work analysed in this study. To model the "Cannone" violin several studies were carried out to identify its structural [18], hygroscopic [19] and its rheological behaviours [20]. In order to develop a hygroscopic model of the violin during its use, a series of environmental and mass measurements were recorded during nine concerts. These concerts exhibit quite different environmental sceneries in terms of environmental conditions, concert duration, and violin
Springer Open

(c) The Author(s) 2020. This article is licensed under a Creative Commons Attribution 4.0 International License, which permits use, sharing adaptation, distribution and reproduction in any medium or format, as long as you give appropriate credit to the original author(s) and the source, provide a link to the Creative Commons licence, and indicate if changes were made. The images or other third party material in this article are included in the article's Creative Commons licence, unless indicated otherwise in a credit line to the material. If material is not included in the article's Creative Commons licence and your intended use is not permitted by statutory regulation or exceeds the permitted use, you will need to obtain permission directly from the copyright holder. To view a copy of this licence, visit http://creativeco mmons.org/licenses/by/4.0/. The Creative Commons Public Domain Dedication waiver (http://creativecommons.org/publicdomain/ zero/1.0/) applies to the data made available in this article, unless otherwise stated in a credit line to the data. 
mass variation. A previous study [21] already shown that violin mass variation depends mainly on environmental conditions and how the role of the player is negligible. In the present work, a simple hygroscopic model was implemented and run. The numerical results were compared with the actual real mass variation during the concerts. Finally, the model was adapted to the real measurements by an inverse identification procedure with the main purpose to show that Fick's law can be profitably used in order to assess the mass transfer of a historic and complex object such as a violin. A simplified model approach was chosen because most of the inputs needed to define a detailed approach to diffusion for a historical violin are unknown. In particular: (1) the permeability of varnishes is unknown; (2) the different wear of the varnishes it is unknown and its effect on permeability is difficult to be determined; (3) other treatments of the wooden material are unknown such as salts applied on the surface as a primer; (4) the effect of aging on the degradation of wood cell wall polymers and its effect on the physical and mechanical properties of wood; (5) there could be an asymmetric aging of wood from the varnished and unvarnished parts; (6) the diffusion coefficient of the wood used in the violin can be very different from that coming from literature because wood is a very variable material; (7) the diffusion coefficients in bibliography are available only for a limited number of wood species. Being an analytic FEM model difficult to be implemented without the majority of the input needed, a simplified approach was chosen. The main outcome of this work is how Fick's low can be profitably used to predict mass transfer in historical musical instruments and how a modelling approach based on simplified assumptions can be misleading. A complex finite element approach would not give better results than a simplified approach if most of the input are unknown, and this is often the case of cultural heritage objects where most of the inputs cannot be assessed and are unique of the specific object. For these reasons a tuning of the model on real data is always needed in order to calibrate the model on the object itself. The model tuned with the inverse identification procedure cannot help to understand the mass transfer in the single parts of the violin but only the behaviour of the violin as a whole.

\section{Materials and methods}

\section{Violin geometry and physical properties}

The violin geometry was perfectly defined by a three dimensional high precision scan described in [18]. The total exchanging surface was determined by direct measurement on the three dimensional model using Blender 3D computer graphics software [22] and the NeuroMorph plug-in [23]. The thicknesses of the various parts was determined as the average value calculated after the measurements reported in [24]. In order to set the boundary conditions of the Fick's solver, the violin hygroscopic system was simplified by considering the parts with low surface to volume ratio as impervious. The same was done for the varnished sides of the violin parts. According to these assumptions the following parts of the violin were considered as not exchanging moisture: the scroll and the pegbox because both varnished and with low surface volume ratio; the pegs because with low surface to volume ratio; the fingerboard and the tailpiece because made of ebony wood well known to be a specie very long to dry [25] and consequently with a very low diffusion coefficient. The parts of the violin with an active role in the model were consequently considered: the sound board, the ribs and the back face which are considered to be semi permeable (permeable on the internal surface and impervious on the external varnished side). The assumption of different permeability of the external and internal surface of the sound board is supported by the measurement of flying wood consequent to an environmental humidity variation as documented in [19]. These parts, for the "Cannone" violin and for most of the existing violins, are made of spruce (Picea abies L.) for the sound board and of sycamore maple (Acer pseudoplatanus L.) for the back face and the ribs. All these parts are usually radially oriented in order to minimise shrinkage and swelling (since the radial shrinkage coefficient is commonly in the order of one half of the tangential one). Being the moisture exchanging wood mass unknown, it was determined by multiplying the volume of the parts by the spruce or sycamore maple densities reported in [26]. The value determined in [26] for a selected number of historical violins was considered more consistent than the wooden literature since the material used for violin making is carefully selected by stringed instrument makers [27-29]. This material in fact, usually present low density compared to the average values of the species reported in literature. The mass of the non exchanging parts was determined as the difference between the known violin mass of $436.6 \mathrm{~g}$ at the conservation conditions $\left(54 \%\right.$ relative humidity and $\left.21{ }^{\circ} \mathrm{C}\right)$ and the mass of the exchanging parts determined as described above. The dry mass to be used in the modelling was determined by supposing the whole violin to be at an average moisture content of $10 \%$. These data are summarised in Table 1.

\section{Model implementation}

The single moisture content of each wooden part is strongly dependent with the surrounding environment. Consequently, the violin moisture content in the conservation condition can be determined using the isothermal sorption curve. In this calculation, the effect of the temperature, in the range variations we 
Table 1 The violin parts involved in the modelling and their physical and geometrical properties

\begin{tabular}{|c|c|c|c|c|}
\hline Violin elements & Wood species (orientation) & $\begin{array}{l}\text { Surface* } \\
\left(\mathrm{mm}^{2}\right) \times \text { thickness }(\mathrm{mm})\end{array}$ & $\begin{array}{l}\text { Density } \\
\left(\mathrm{kg} \mathrm{m}^{-3}\right)\end{array}$ & $\operatorname{Mass}^{* *}(g)$ \\
\hline References & [24] & {$[24]$} & [26] & \\
\hline Sound board & $\begin{array}{l}\text { Spruce } \\
\text { Picea abies L. } \\
\text { Radial sawing } \\
\text { Tangential diffusion }\end{array}$ & $51.450 \times 3.10$ & 370 & 59.0 \\
\hline Ribs & $\begin{array}{l}\text { Sycamore maple } \\
\text { Acer pseudoplatanus L. } \\
\text { Radial sawing } \\
\text { Tangential diffusion }\end{array}$ & $32.134 \times 1.15$ & 587 & 21.7 \\
\hline \multirow[t]{4}{*}{ Back face } & $\begin{array}{l}\text { Sycamore maple } \\
\text { Acer pseudoplatanus L. } \\
\text { Radial sawing } \\
\text { Tangential diffusion }\end{array}$ & $52.085 \times 4.40$ & 587 & 134.6 \\
\hline & Violin mass exchanging water (g) & & & 215.3 \\
\hline & Violin total mass (g) & & & 436.6 \\
\hline & Violin mass not exchanging water (g) & & & 221.3 \\
\hline
\end{tabular}

* Exchanging surface with environment. ${ }^{* *}$ The masses are relative to the conservation conditions of $54 \%$ of relative humidity and $21{ }^{\circ} \mathrm{C}$, corresponding to about $10 \%$ of moisture content

are considering, can be neglected as reported by [21]. Therefore, GAB (Guggenheim-Anderson-de Boer) isotherm at $20{ }^{\circ} \mathrm{C}$ as from Equation [1] was adopted in order to calculate the equilibrium moisture content $(w)$ :

$$
w=w_{m} \frac{C \cdot K \cdot R H}{(1-K \cdot H)(1-K \cdot R H+C \cdot K \cdot R H)}
$$

where $w$ is the equilibrium moisture content, $R H$ is the relative humidity, and $w_{m}, K$, and $C$ are three geometrical parameters suitable to describe sorption curves (each of them having a physical meaning not explained here for the sake of brevity).To set the GAB model, the experimental data reported in $[2,30]$ for spruce and maple sycamore were used and are reported in Table 2 . The hysteresis of sorption is not considered in the present work, only the average between the sorption and desorption curves of the GAB model was used.

After a literature review a wide set of diffusion coefficients for spruce wood was found, showing how these coefficients are strongly dependent on the experimental setup. It explains why it is very hard to use coefficients from literature in generalised models. For the spruce diffusion coefficient, the one provided by [31] was selected. For maple the opposite scenario was found where only one paper [32] reported such coefficients for (Acer pseudoplatanus L.). Because [32] reports that the diffusion coefficient is thickness dependent the values were identified in function of the violin elements thicknesses (see Table 1). Coefficients for sugar maple (Acer saccharinum L.) were also available but neglected being sugar maple quite different from sycamore maple. The values of the selected diffusion coefficients are also reported in Table 2.

The isotherm of water vapour adsorption/desorption and average line for spruce and sycamore maple as computed from GAB model as from [2] are reported in Fig. 1.

\section{Moisture diffusion and Fick's law adaptation to the problem}

The mass transfer of water in hygroscopic materials such as wood depends on the diffusion of bound water through cell walls and of water vapour in the lumens, both being in equilibrium [33-35]. At the macroscopic scale, the overall effect is often modelled as a global diffusion with a unique diffusivity tensor $\overline{\bar{D}}$ [11] containing the mass diffusion coefficients in the three anatomical directions. The varnished surface was supposed as not exchanging moisture (impervious boundary condition), while the non-coated face of the boundary tends to the computed equilibrium moisture content. Considering the thicknesses and the radial orientation (then tangential diffusion) of the board 
Table 2 Model input for moisture content calculation and moisture diffusion for the water exchanging elements

\begin{tabular}{|c|c|c|c|c|c|c|}
\hline \multirow[t]{3}{*}{ Violin elements } & \multicolumn{3}{|c|}{ GAB isothermal sorption curve parameters } & \multirow{2}{*}{\multicolumn{3}{|c|}{$\begin{array}{l}\text { Diffusion coefficients } \\
D_{\mathrm{T}}\left(\times 10^{-10} \mathrm{~m}^{2} \mathrm{~s}^{-1}\right)\end{array}$}} \\
\hline & \multirow{2}{*}{$\begin{array}{l}W_{m}(\%) \\
{[2,30]}\end{array}$} & \multirow[t]{2}{*}{$C$ (adim) } & \multirow[t]{2}{*}{$K($ adim $)$} & & & \\
\hline & & & & Literature based model & & $\begin{array}{l}\text { Inverse } \\
\text { identification model }\end{array}$ \\
\hline Sound board & 7.39 & 11.265 & 0.72 & {$[31]$} & 0.452 & 0.452 \\
\hline Ribs & 9.58 & 8.010 & 0.44 & [32] for $1.15 \mathrm{~mm}$ thickness & 0.015 & 1.300 \\
\hline Back face & & & & [32] for $4.40 \mathrm{~mm}$ thickness & 0.110 & \\
\hline
\end{tabular}

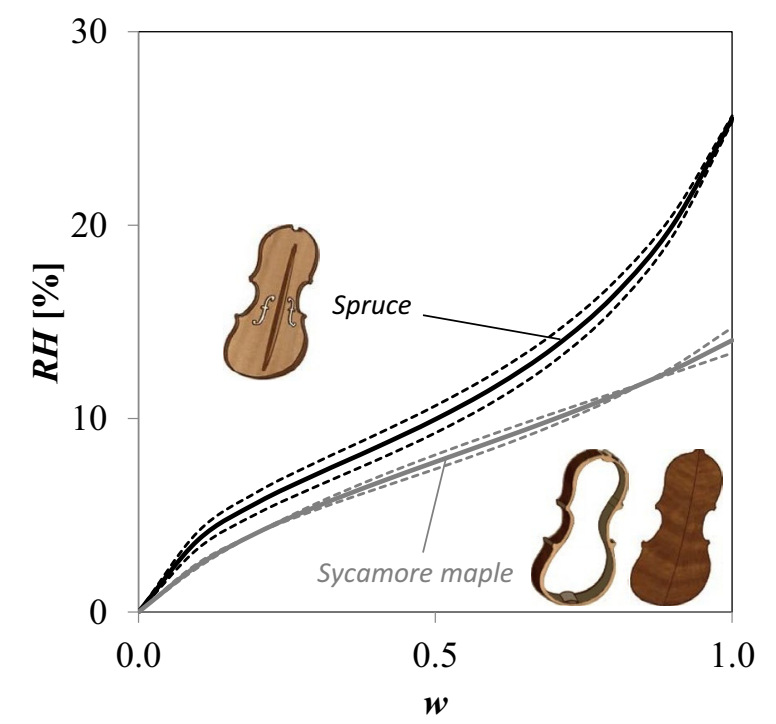

Fig. 1 Average isotherm of water vapour at $20^{\circ} \mathrm{C}$ for spruce and sycamore maple with the adsorption and desorption branches reported in non continuous line (NB: the hysteresis of sorption is not considered in this study), as computed by the GAB model using the parameters presented by [2]

composing the sound-board, the back face and the ribs, we assumed that the moisture diffusion occurs only in the tangential direction. Accordingly, the unidirectional diffusion process is assumed to follow the Fick's law and the flux of moisture can be written as in Equation [2]:

$$
\frac{\partial w}{\partial t}=D_{\mathrm{T}} \frac{\partial^{2} w}{\partial x^{2}}
$$

where $w$ is the moisture content, $t$ the time, $x$ the position along the diffusion direction (here tangential across the wooden part thicknesses), and $D_{\mathrm{T}}$ the moisture diffusion coefficient of the considered wood specie in the tangential direction. This equation could have a closed-form analytical solution by some approximations as proven by Boltzman [36] and recently improved mathematically by Okino [37]. Some other authors propose complicated solutions based on a physical model for porous media [34] for its accuracy and performances to describe any drying process. The Darcy's law [38] to describe the flow of a water through a porous medium approach is not relevant here since the violin wood moisture content remains way under the fibre saturation point. Nevertheless, in this work, being the diffusion mainly unidirectional, an explicit Euler method for time and space integration scheme was used for its ease of use and implementation (even if less fast). The temperature outside and inside the violin, according to [21], was found to not affect the global violin behaviour; therefore it was considered as not having effects on the diffusion coefficient neither. The model was iterated on the data of the nine concerts, reported in [21], with the main inputs summarised in Table 3. The relative humidity variation $(\Delta R H)$ between the showcase and the environment surrounding the violin during concerts was used as boundary condition in the diffusion solver. 


\section{Model tuning by inverse identification}

The model was first of all run with the explained simplifications and diffusion coefficients coming from literature. As a second step, an inverse identification procedure was used to tune the model to the real mass variations. Among different inverse identification strategies, the sycamore maple tangential diffusion coefficient was chosen as variable for model optimisation. This leads the coefficients to lose their physical meaning but allow to include in the model all the uncertainties in the definition of the boundary conditions. To do so, the model was run on the meaningful experimental data constitutes by the nine real concerts in order to identify the estimated maple tangential diffusion coefficient $\tilde{D}_{\text {T_maple. This could seem a sig- }}$ nificant issue considering the different strong assumptions adopted in the modelling strategy, such as the impervious coated surfaces whom actual permeability is unknown. However, being based on a significant extended experimental data (9 concerts with different environment patterns), this identified parameter results quite accurate to reach the target of achieving a robust hygroscopic model of the "Cannone" violin. Obviously, the estimated $\tilde{D}_{\mathrm{T} \_ \text {maple }}$ does not result in a meaningful maple diffusion coefficient because it reflects in its single value the direct effects of the overall simplifications applied.

\section{Results and discussion}

Running model with simplified assumptions and diffusion coefficients from literature

The data provided in Table 2 arising directly from literature are run with the model described in the previous section and the results are plotted in Fig. 2. $\Delta R H$ reports the difference in relative humidity between the average conservation relative humidity and the average relative humidity recorded during the concert. $\Delta M$ stands for the mass variation of the violin during the concert because moisture adsorption/desorption, TOC is the Time Outside the showcase and corresponds to the amount of time the violin spends outside the showcase for the concert. The mass variations are referred to one unit of time and are reported as $\triangle M / T O C(\mathrm{~g} / \mathrm{h})$. It better allows to compare the concerts in a single plot (Fig. 2b).

As can be observed from Fig. 2a, both experimental and numerical trends of violin mass variations for unit of time $(\triangle M / T O C)$ vs. variation of relative humidity $(\Delta R H)$ are linear. This was already shown and explained in [21] as a result of the short duration of the concerts and of the limited variations in relative humidity that makes the adsorption isotherm and the adsorption process quiet linear. However, numerical data vs. measured data are very far from each other as shown in Fig. 2b. It clearly shows how uncritically apply diffusion coefficients from literature results in a model able to explain only a small fraction of the real violin behaviour $\left(R^{2}=0.27\right)$. This lack of predictive capacity of the model can be ascribed to the hard simplifications, to the inability to determine the permeability of the varnishes, to the variability of wood, to the unknown effect of wood aging and diffusion coefficients determined experimentally. A lot of uncertainties that cannot be avoided nor minimised when working with cultural heritage.

\section{Model tuning by inverse identification}

The above-mentioned limits make evident how modelling cultural heritage objects by simplified assumptions and literature data is impossible, misleading and wrong. It is then essential to modify the approach by tuning general laws to the real object. An inverse identification of sycamore maple diffusion coefficient was then attempted in order to verify if the Fick's law could profitably model the global behaviour of the violin. Indeed, the imposed boundary conditions of the model in the inverse

Table 3 Conditions in the showcase and in the concert rooms used as boundary conditions for the diffusion problem

\begin{tabular}{|c|c|c|c|c|c|c|c|}
\hline Concerts ID & Violin player's name & $R H_{\text {showcase }}(\%)$ & $R H_{\text {concert }}(\%)$ & $\Delta R H(\%)$ & TOC (h) & $\Delta M_{\text {exp }}(\mathrm{g})$ & $\Delta M / T O C\left(\mathrm{~g} \mathrm{~h}^{-1}\right)$ \\
\hline 1 & Mario trabucco & 53.9 & 61.1 & +7.2 & 3.00 & 0.38 & 0.13 \\
\hline 2 & Feng ning & & 40.8 & -13.1 & 2.75 & -0.65 & -0.24 \\
\hline 3 & Feng ning & & 41.4 & -12.5 & 2.75 & -0.37 & -0.13 \\
\hline 4 & Peter sheppard & & 42.9 & -11.0 & 2.00 & -0.39 & -0.19 \\
\hline 5 & Peter sheppard & & 47.4 & -6.5 & 4.00 & -0.25 & -0.06 \\
\hline 6 & Mario trabucco & & 61.7 & +7.8 & 3.25 & 0.47 & 0.14 \\
\hline 7 & Salvatore accardo & & 50.9 & -3.0 & 4.25 & -0.15 & -0.04 \\
\hline 8 & Mario trabucco & & 55.3 & +1.4 & 4.00 & 0.08 & 0.02 \\
\hline 9 & Mario trabucco & & 38.8 & -15.1 & 4.50 & -0.86 & -0.19 \\
\hline
\end{tabular}

$R H_{\text {showcase }}$ isn the average $R H$ level in the conservation showcase, $R H_{\text {concert }}$ is the average environmental $R H$ measured during the whole period the violin was outside the case for the concert, $\Delta R H$ is $\left(R H_{\text {concert }}-R H_{\text {showcase }}\right), T O C$ is the time the violin was kept outside the showcase for the concert, $\Delta M_{\text {exp }}$ is the mass variation measured as the difference between the value of mass when the showcase is opened and the value of mass just before closing again the instrument in the conservation showcase 

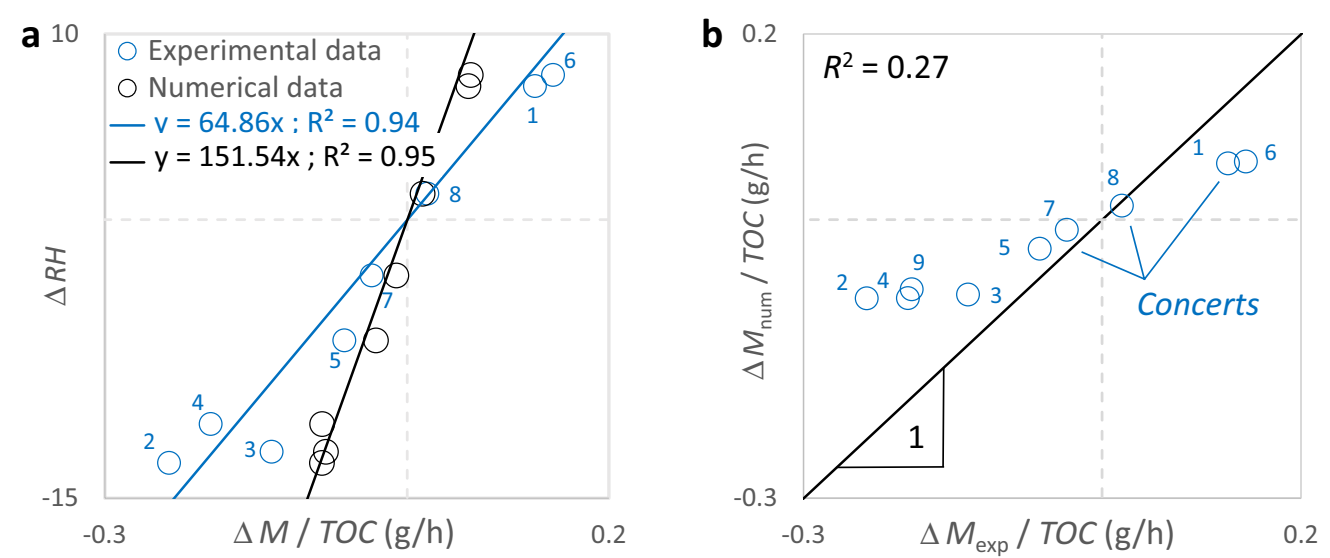

Fig. 2 a Result of the modelling using diffusion coefficients from literature for both sycamore maple and spruce, of the nine concerts monitored, and $\mathbf{b}$ representation of this model accuracy to predict the mass variation during the concerts. The line corresponds to a perfect correspondance between the simulated concert and the experimental ones

identification process play a fundamental role resuming all of them in that single peculiar optimised value for the considered problem and solver set up. The diffusion coefficient identified is actually a hybrid (experimental/ model) coefficient that cannot be considered as a realistic for wood but that include all the simplified assumptions and allow to solve the diffusion problem for the violin considered as a whole. Because the main anatomical flow direction is tangential, only one tangential diffusion coefficient was determined $\left(\tilde{D}_{\mathrm{T} \_ \text {maple }}\right)$. Matlab software for mathematical computing was used to set-up the model and to process the inverse identification. The model was iterated on progressive variations of $\tilde{D}_{\text {T_maple }}$ ranging from $0.1 \times 10^{-10}$ to $2.5 \times 10^{-10} \mathrm{~m}^{2} \mathrm{~s}^{-1}$ and run on the overall set of concerts. The average error was computed as from Equation [3] where $\Delta M_{\exp }$ is the real mass variations recorded during concerts and $\Delta M_{\text {num }}$ is the numerical mass variation computed using the model; the inverse identification of $\tilde{D}_{\mathrm{T} \_ \text {maple }}$ is performed by single minimisation of that average error.

$$
\begin{aligned}
& \text { Relative error }\left.\right|_{\tilde{D}_{\text {T maple }}} \\
& =\left.\sqrt{\sum_{1}^{9}\left(\frac{\left(\Delta M_{\text {num }}-\Delta M_{\text {exp }}\right)}{\Delta M_{\text {exp }}} \times 100\right)^{2}}\right|_{\tilde{D}_{\text {T maple }}}
\end{aligned}
$$

The computed relative error was plotted against the iterated diffusion coefficient values and has shown a parabolic trend with a minimum at $\tilde{D}_{\text {T_maple }}=1.30 \times 10^{-10} \mathrm{~m}^{2} \mathrm{~s}^{-1}$. A detail of the plot in the unique minimum area is shown in Fig. 3.

The obtained value of $1.300 \times 10^{-10} \mathrm{~m}^{2} \mathrm{~s}^{-1}$ is much higher than the common value of $0.452 \times 10^{-10} \mathrm{~m}^{2} \mathrm{~s}^{-1}$

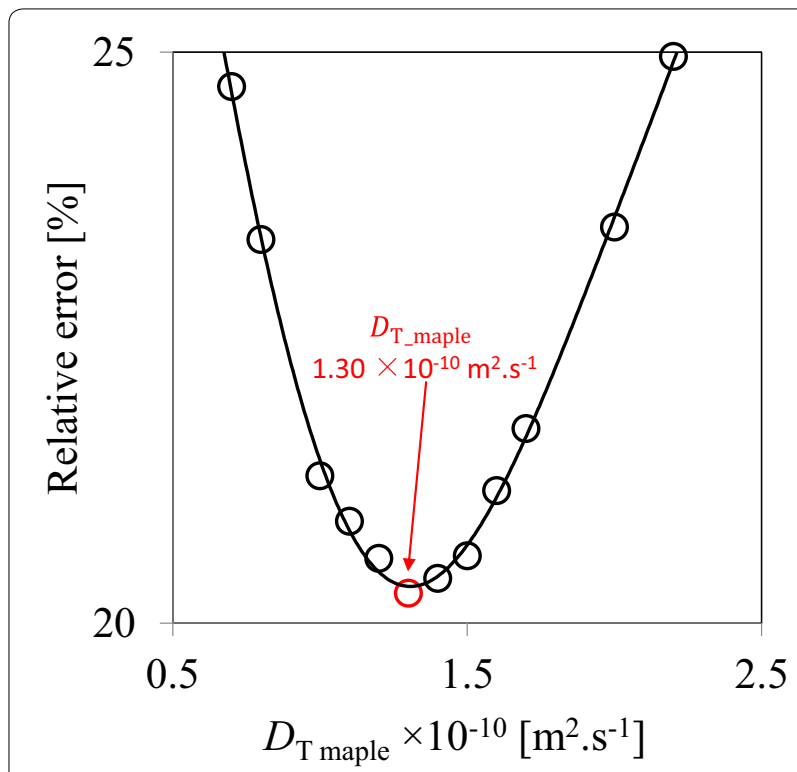

Fig. 3 Sycamore maple mass diffusion coefficient determination by minimisation of the relative error between $\Delta M_{\exp }$ and $\Delta M_{\text {num }}$ over the 9 concerts monitored

used for spruce wood and it is also very far from the value of about $0.100 \times 10^{-10} \mathrm{~m}^{2} \mathrm{~s}^{-1}$ from [32] and $0.069 \times 10^{-10} \mathrm{~m}^{2} \mathrm{~s}^{-1}$ of sugar maple reported by [39]. This high value of diffusion coefficient can easily be explained by the fact the varnishes are not totally impervious and that other parts of the violins exchange water as these considered to be permeable in the simplified model. The experimental and the numerical data are shown in Fig. 4. As it can be observed, in Fig. 4a again, the numerical data present a linear trend as well as the measured data. Furthermore, as from Fig. $4 \mathrm{~b}$, the $88 \%$ of 
$\mathbf{a}$

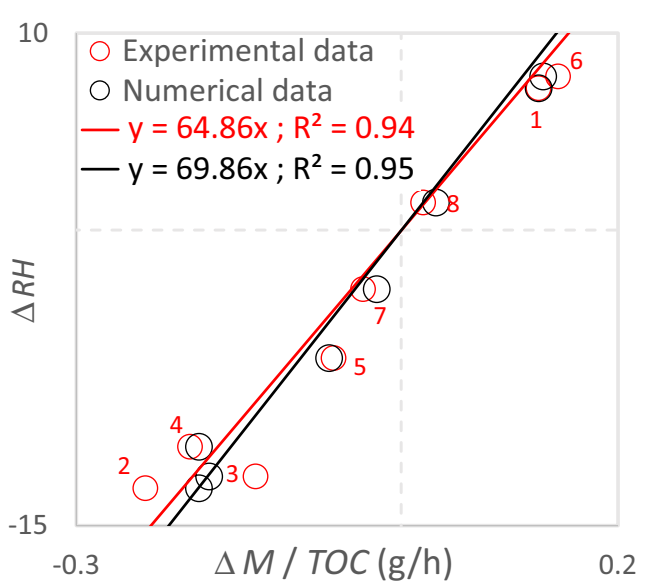

b

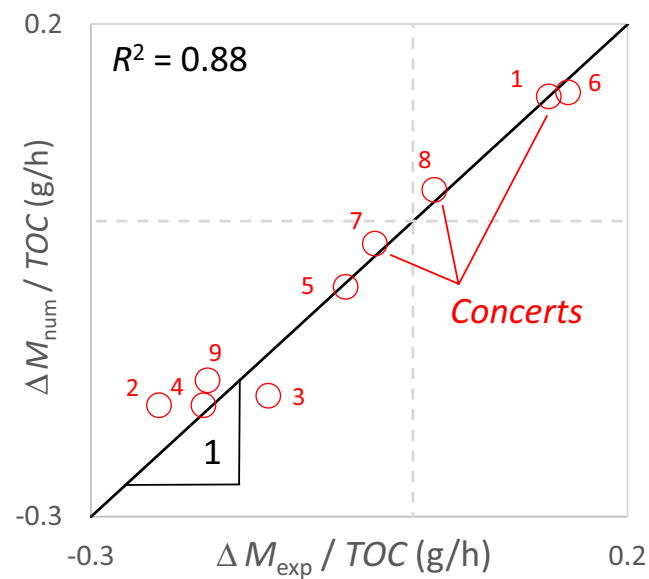

Fig. 4 a Result of the modelling of the nine concerts monitored on top, and $\mathbf{b}$ the representation of the model accuracy to predict the mass variation during the concerts. The line corresponds to a perfect correspondance between the simulated concert and the experimental ones

the mass variation during concerts can be predicted with a model based on Fick's law and be defined as fickian.

Figure 5 provides an example of the model run on the relative humidity variation of the concert number 2 , where the relative humidity steps from an average value of $53.9 \%$ to an average value $49.3 \%$ for a time of about 3 hours. Dashed line also shows the expected behaviour of the violin in case the relative humidity variation persisted until the equilibrium moisture content was reached (about a week).

With a more complex model it could also be interesting to separately predict the mass variation of the soundboard, back face and ribs and the recovery time once the violin is placed back into the conservation showcase after the concert. This step could lead to the development of hygro-mechanical models where deformations and stresses could be predicted with important output in the definition of the conservation duties.

\section{Extension of the model to theoretical cases}

The developed model, once tuned to real conditions, could also be profitably used to predict a large number of virtual concerts in order to evaluate the impact
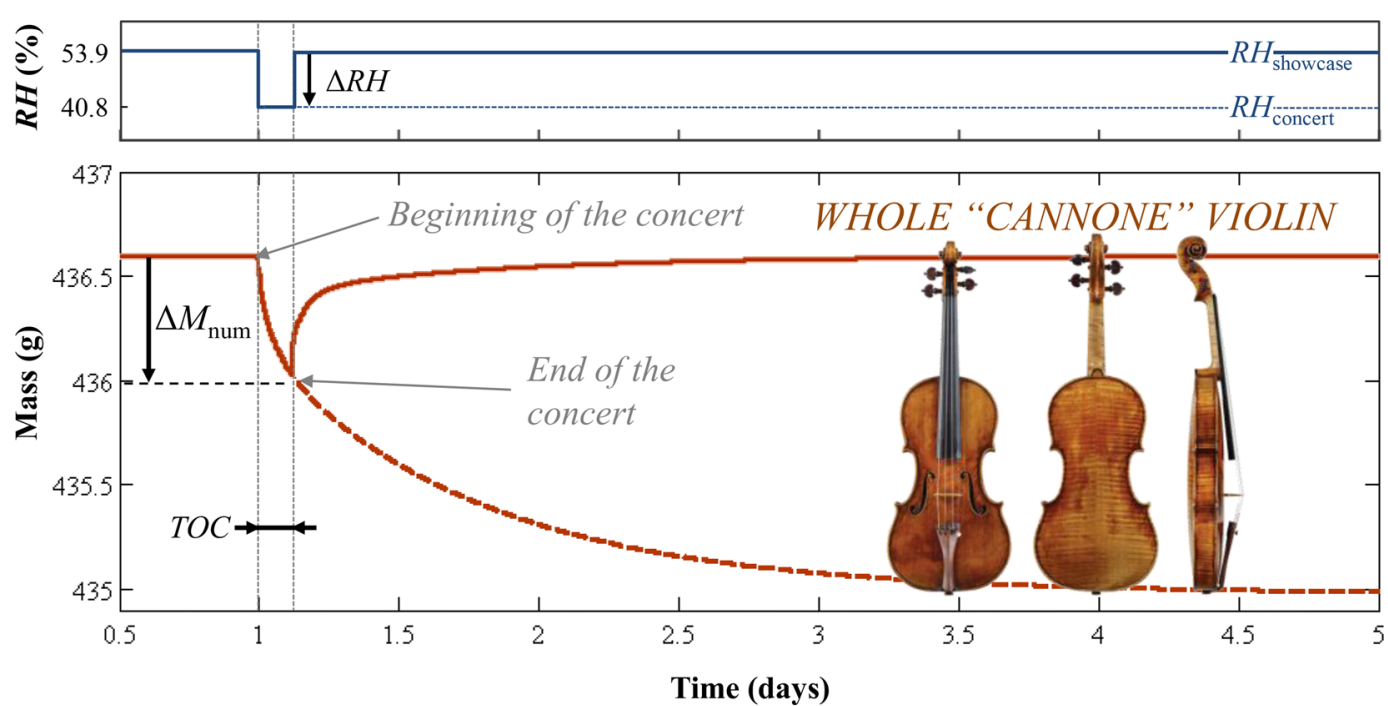

Fig. 5 In plain lines, mass variation $\left(\Delta M_{\text {num }}=-0.57 \mathrm{~g}\right.$ ) of the "Cannone" violin (on bottom) and its different exchanging parts (on top) over time during the concert number $2\left(\triangle R H=13.1 \%\right.$, concert duration $T O C=2.75 \mathrm{~h}$ and the mass variation $\left.\Delta M_{\text {exp }}=-0.65 \mathrm{~g}\right)$. In the middle part is represented the relative humidity conditions imposed to the violin during the concert. In dashed line is figured the mass variation if the violin was kept in the concert until reaching its mass equilibrium (after about 6 days) 
of any concert on the high valuable instrument. The model was run on 1000 randomly simulated relative humidity variations between -20 and $+20 \%$ from the conservation conditions and for TOC (Time Outside the showcase) ranging from 0.5 to $10 \mathrm{~h}$. The result of this simulation is shown in Fig. 6. As can be observed, the simulated concerts with a duration between 2 and $5 \mathrm{~h}$ (as the nine real concerts analysed in this paperhighlighted with red circles), are in line with the experimental data. This quasi-linear behaviour in this range, well documented by [21], is due to the fact that Fick's law diffusion process can be approximate by a linear behaviour when considering very short time and non-extreme relative humidity variations even though the moisture diffusion is far from behaving linearly. Nonetheless, by increasing the time of the concert, the behaviour of the instrument becomes more and more non-linear and justifies the use of Fick's law to assess the real behaviour under such conditions.

\section{Conclusions}

The use of literature diffusion coefficients and simplified boundary conditions to predict the hygroscopic behaviour of a complex object such as a violin was found to be wrong and potentially hardly misleading. Very wrong choices could be undertaken when based on such assumptions. This approach leads the model to explain only a small fraction of the real mass variations during concerts $\left(R^{2}=0.27\right)$. Because most of the inputs of the model are unknown (wood aging, permeability of the varnishes or unknown treatments, incertitude of

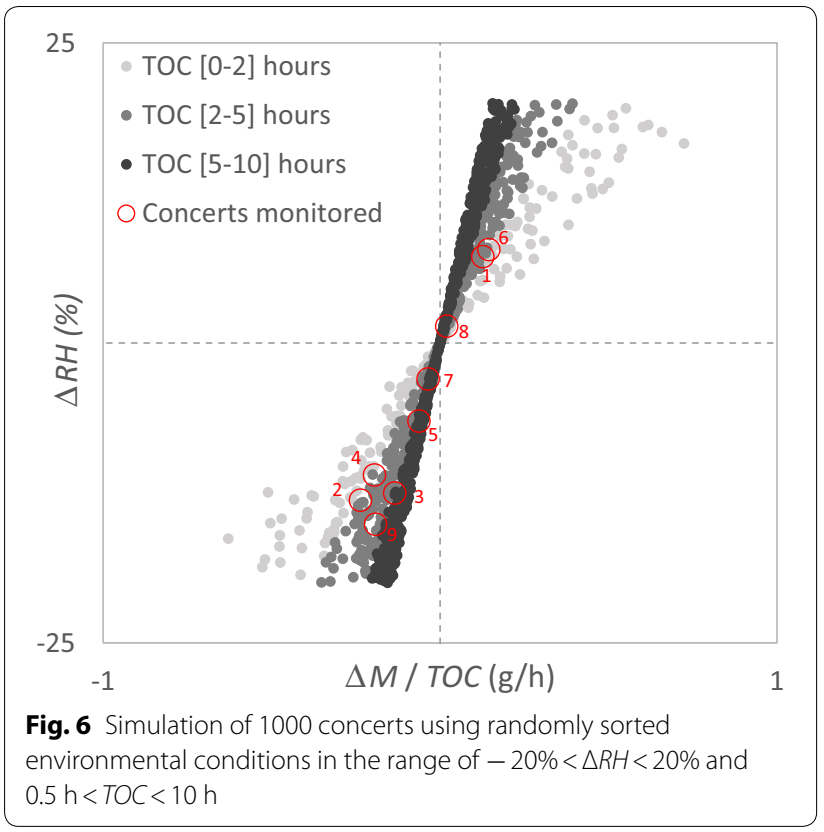

diffusion coefficients, non-homogeneity of the materials) and not easily measurable without exposing a cultural heritage piece to unnecessary risks, because some simplified boundaries are necessary, a model based on non-destructive procedures and tuned on real data is always necessary.

The model was then tuned on real data to verify the suitability of Fick's law to predict the violin hygroscopic behaviour. The tuning was done through inverse determination of sycamore maple diffusion coefficient by iterative error minimisation. With this procedure the diffusion coefficients lose their physical meaning leading to include the errors due to simplified boundaries and lack of information into the diffusion coefficients. Nonetheless, thanks to such procedure general conclusion on the specific "Cannone" artefact can be drawn. This approach leads the model to carefully explain $\left(R^{2}=0.88\right)$ the real mass variation of the violin as a consequence of the environment relative humidity variation during concerts. This work does not intend to promote modelling strategies but only verify that Fick's law, after a proper tuning, could profitably be used to predict the hygroscopic behaviour of a cultural heritage complex object such as a violin The main outcome is that a numerical approach without coupling with experimental observation can drive to very wrong results. By extension, such approach results to be a valuable first step to a more complex hygro-mechanical model needed to estimate the risk of playing valuable cultural heritage musical instruments in order to define a conservation strategy.

\section{Abbreviations}

w: Equilibrium moisture content; $R H$ : Relative humidity; $w_{m}, K$ and $C:$ Geometrical parameters suitable to describe sorption curves with GAB system; $D_{T}$ : Diffusion coefficient; t: Time; $\tilde{D}_{\text {T }}$ maple: Estimated maple tangential diffusion coefficient; $\Delta M$ : Mass variation; $\Delta M_{\text {exp }}$ : Real mass variations recorded during concerts; $\Delta M_{\text {num }}$ : Numerical mass variation computed using the model; TOC: Time outside the showcase.

\section{Acknowledgements}

We would like to thank the bowed instrument makers and restorers Bruce Carlson, Alberto Giordano and Pio Montanari who assist the conservation of the "Cannone" violin. Dr Anna Rita Certo and Dr Fabiana Virgilio, working for Genova Municipality for their cooperation.

\section{Authors' contributions}

BM: developed the Matlab code for the inverse calculation of the diffusion coefficient and for the modelling of the hygrothermal behaviour of the violin, has written part of the paper. GG: defined the experimental protocol, have measured the surfaces of the water exchanging parts of the violin, monitored the mass variation during concerts and has written part of the paper. MF: implemented the research program with Genova municipality, defined the experimental protocol and monitored the mass variation during concerts. All authors read and approved the final manuscript.

Funding

The research is partly funded by Genova Municipality. 


\section{Availability of data and materials}

All data analysed during this study are included in this published article.

\section{Competing interests}

The authors declare that they have no competing interests.

\begin{abstract}
Author details
${ }^{1}$ Arts et Metiers Institute of Technology, LaBoMaP, HESAM Université, 1 rue Porte de Paris, 71250 Cluny, France. ${ }^{2}$ Department of Agriculture, Food, Environment and Forestry (DAGRI), University of Florence, Via S. Bonaventura 13, 50145 Florence, Italy.
\end{abstract}

Received: 29 October 2019 Accepted: 25 February 2020

Published online: 05 March 2020

\section{References}

1. Mazzanti P, Togni M, Uzielli L. Drying shrinkage and mechanical properties of poplar wood (Populus alba L.) across the grain. J Cult Herit. 2012;13:S85-9. https://doi.org/10.1016/j.culher.2012.03.015.

2. Kozłowska A, Kozłowski R. Analysis of water adsorption by wood using the Guggenheim-Anderson-de Boer equation. Eur J Wood Wood Prod. 2012;70(4):445-51. https://doi.org/10.1007/s00107-011-0571-x.

3. Hunt D. Properties of wood in the conservation of historical wooden artifacts. J Cult Herit. 2012;13(3):S10-5.

4. Mazzanti P, Colmars J, Gril J, Hunt D, Uzielli L. A hygro-mechanical analysis of poplar wood along the tangential direction by restrained swelling test. Wood Sci Technol. 2014;48(4):673-87. https://doi. org/10.1007/s00226-014-0633-4.

5. Marcon B, Mazzanti P, Uzielli L, Cocchi L, Dureisseix D, Gril J. Mechanical study of a support system for cupping control of panel paintings combining crossbars and springs. J Cult Herit. 2012;13(3):S109-17.

6. Uzielli L, Dionisi-Vici P, Gril J. Physical and mechanical characterization of the support. New York, Abrams: Mona Lisa-Inside Paint; 2006. p. 48-9.

7. Perré $P$, Rémond R, Gril J. Simulation of the effects of ambient variations. In: Mohen J-P, Menu M, Mottin B, editors. Mona Lisa-Inside Paint. New York: Abrams; 2006. p. 50-1.

8. Dureisseix D, Gril J, Arnould O. Mechanical modeling of the activity of the flexible frame. In: Mohen J-P, Menu M, Mottin B, editors. Mona LisaInside Paint. New York: Abrams; 2006. p. 50-1.

9. Rachwał B, Bratasz Ł, Łukomski M, Kozłowski R. Response of wood supports in panel paintings subjected to changing climate conditions. Strain. 2012;48:366-74.

10. Mecklenburg MF, Tumosa CS, Erhardt D. Structural response of painted wood surfaces to changes in ambient relative humidity. In: Dorge $V$, Howlett FC, editors. Paint wood hist conserv. Los Angeles: The Getty Conservation Institute; 1998. p. 464-83.

11. Dureisseix D, Marcon B. A partitioning strategy for the coupled hygromechanical analysis with application to wood structures of cultural heritage. Int J Numer Methods Eng. 2011;88:228-56.

12. Gebhardt C, Konopka D, Börner A, Mäder M, Kaliske M. Hygromechanical numerical investigations of a wooden panel painting from "Katharinenaltar" by Lucas Cranach the elder. J Cult Herit. 2018;29:1-9. https://doi.org/10.1016/j.culher.2017.08.003.

13. Riparbelli L, Brémand F, Dionisi-Vici P, Dupré J-C, Goli G, Hesser F, et al. Studies for the Mona Lisa conservation: the implementation of its panel's Digital-Twin. CompWood. Växjö, Sweden. Växjö: Linnaeus University in Växjö; 2019; June 17-19.

14. Konopka D, Ehricht S, Kaliske M. Hygro-mechanical investigations of clavichord replica at cyclic climate load: experiments and simulations. J Cult Herit. 2019;36:210-21. https://doi.org/10.1016/j.culhe r.2018.07.006

15. Konopka D, Gebhardt C, Kaliske M. Numerical modelling of wooden structures. J Cult Herit. 2017;27:S93-102. https://doi.org/10.1016/j. culher.2015.09.008.

16. Lechner T, Bjurhager I, Kliger RI. Strategy for developing a future support system for the Vasawarship and evaluating its mechanical properties. Herit Sci. 2013;1(1):35. https://doi.org/10.1186/2050-7445-1-35.
17. Rossi Rognoni G, Barry AM. 2nd Annual Conference of COST Action FP1302 WoodMusICK. In: Rossi Rognoni G, Barry AM, editors. Eff Play early mod music instruments. London; 2015. p. 100

18. Fioravanti M, Goli G, Carlson B. Structural assessment and measurement of the elastic deformation of historical violins: the case study of the Guarneri 'del Gesù' violin (1743) known as the 'Cannone'. J Cult Herit. 2012;13:145-53.

19. Goli G, Fioravanti M, Busoni S, Carlson B, Mazzanti P. Measurement and modelling of mass and dimensional variations of historic violins subjected to thermo-hygrometric variations: the case study of the Guarneri "del Gesù" violin (1743) known as the "Cannone". J Cult Herit. 2012;13(3):S154-60.

20. Fioravanti M, Goli G, Carlson B. Viscoelastic and mechano-sorptive studies applied to the conservation of historical violins: a case study of the Guarneri "del Gesù" violin (1743) known as the "Cannone". J Cult Herit. 2013;14(4):297-303.

21. Goli G, Marcon B, Busoni L, Carlson B, Cavalli A, Giordano A, Mazzanti P, Montanari $\mathrm{P}$, Togni M, Fioravanti M. Antique violins: effect of the player on the moisture content. Int J Conserv Sci. 2017;8(2):177-86.

22. Blender Fundation. Blender. Blender Fund. https://www.blender.org/.

23. EPFL. NeuroMorph. Scr. Ext. Blender Softw. https://en.blender.org/ index.php/Extensions:2.6/Py/Scripts/NeuroMorph.

24. Scrollavezza R, Giordano A, Montanari P. Measurements of the "Paganini" Guarneri "del Gesù" 1742 (II Cannone)-'Il violino di Paganini: la storia, la voce, I'immagine-Salvatore Accardo suona il Guarneri del Gesù di Paganini'. Genova: Dynamic-The Strad; 1995.

25. CIRAD. Tropix 7.0. CIRAD; 2015

26. Stoel BC, Borman TM. A Comparison of wood density between classical cremonese and modern violins. Grama A, editor. PLoS ONE. 2008;3:e2554. http://dx.plos.org/10.1371/journal.pone.0002554.

27. Haines DW. The essential mechanical properties of wood prepared for musical instruments. Catgut Acoust Soc J. 2000;4:20-32.

28. Ono T, Norimoto M. On physical criteria for the selection of wood for soundboards of musical instruments. Rheol Acta. 1984;23(6):652-6. https://doi.org/10.1007/bf01438805.

29. Brémaud I. Acoustical properties of wood in string instruments soundboards and tuned idiophones: biological and cultural diversity. J Acoust Soc Am. 2012;131:807-18.

30. Peralta PN. Sorption of moisture by wood within a limited range of relative humidities. Wood Fiber Sci. 1995;27:13-21.

31. Froidevaux J. Wood and paint layers aging and risk analysis of ancient panel painting. Mechanics of materials. Montpellier: Université Montpellier II-Sciences et Techniques du Languedoc; 2012.

32. Pfriem A, Zauer M. Alteration of the Unsteady Sorption Behaviour of Spruce and Maple due to Thermal Treatment. Ger Res. 2009;363-70.

33. Olek W, Perré $P$, Weres J. Inverse analysis of the transient bound water diffusion in wood. Holzforschung. 2005:59:38-45.

34. Perre P, Pierre F, Joel C, Ayouz M. Determination of the mass diffusion coefficient based on the relative humidity measured at the back face of the sample during unsteady regimes. Dry Technol. 2015;In Press. p. $1-8$.

35. Konopka D, Kaliske M. Transient multi-FICKian hygro-mechanical analysis of wood. Comput Struct. 2018;197:12-27. https://doi.org/10.1016/j. compstruc.2017.11.012.

36. Boltzmann L. Zur integration der diffusionscoefficientent. Ann Phys. 1894;53:959-64.

37. Okino T. New mathematical solution for analyzing interdiffusion problems. Mater Trans. 2011;52:2220-7.

38. Darcy $H$. Les fontaines publiques de la ville de Dijon: détermination des lois d'écoulement de l'eau à travers le sable. Victor Dalmont eds. 1856.

39. Hartley ID, Schneider MH. Water vapour diffusion and adsorption characteristics of sugar maple (Acer saccharum, Marsh) wood polymer composites. Wood Sci Technol. 1993;27:421-7. https://doi.org/10.1007/ BF00193864.

\section{Publisher's Note}

Springer Nature remains neutral with regard to jurisdictional claims in published maps and institutional affiliations. 